\title{
MRKH syndrome: a review of literature
}

\author{
Nidhi Jain*, Jyotsna Harlalka Kamra
}

Department of Obstetrics and Gynecology, Maharaja Agarsein Medical College, Agroha, Hisar, Haryana, India

Received: 12 November 2018

Accepted: 16 November 2018

\section{*Correspondence:}

Dr. Nidhi Jain,

E-mail: nidhijain270587@gmail.com

Copyright: (c) the author(s), publisher and licensee Medip Academy. This is an open-access article distributed under the terms of the Creative Commons Attribution Non-Commercial License, which permits unrestricted non-commercial use, distribution, and reproduction in any medium, provided the original work is properly cited.

\begin{abstract}
Primary amenorrhea is defined as failure to achieve menarche till age of 14 years in absence of normal secondary sexual characters or till 16 years irrespective of secondary sexual characters. The most common cause of primary amenorrhea is gonadal pathology followed by Mayer-Rokitansky-Küster-Hauser syndrome (MRKH syndrome). MRKH syndrome is a rare congenital disorder characterised by uterine and vaginal aplasia. It occurs due to failure of development of Müllerian duct. Its incidence is 1 per 4500 female births. Mostly girls present with primary amenorrhea. It is characterised by presence of normal secondary sexual characteristics, normal $46 \mathrm{XX}$ genotype, normal ovarian function in most of the cases and absent or underdeveloped uterus and upper part (2/3) of vagina. It is of two types: type A is isolated type while type B is associated with other renal/skeletal/cardiac anomalies. Treatment includes psychological counselling and vaginoplasty. Vaginoplasty can be done by various non-surgical and surgical techniques. The authors hereby review the literature of MRKH syndrome regarding its embryology, etiopathogenesis, approach to work up and management.
\end{abstract}

Keywords: Amenorrhea, MRKH syndrome, Müllerian duct

\section{INTRODUCTION}

MRKH syndrome is a rare congenital disorder characterised by uterine and vaginal aplasia. It occurs due to failure of development of Müllerian duct. Its incidence is 1 per 4500 female births. ${ }^{1-3}$

Typically, young girls with this syndrome presents with primary amenorrhea. It is characterised by normal secondary sexual characteristics, normal $46 \quad \mathrm{XX}$ genotype, normal ovarian function in most of the cases and absent or underdeveloped uterus and upper part (2/3) of vagina.

It is of two types: type A and Type B. Type A is an isolated variety in which uterus, cervix and upper $2 / 3$ of vagina is absent while bilateral ovaries are normal. No other anomaly is associated. Type B is associated with various other anomalies such as renal anomalies, skeletal anomalies and cardiac anomalies. Bilateral ovaries might be absent in type B variety. Most common anomaly in type $\mathrm{B}$ syndrome is renal anomalies.

Diagnosis is based on radiological findings. Ultrasound pelvis is the first investigation of choice. Absence of uterus and cervix is found on sonography. MRI pelvis is done to confirm the diagnosis. MRI abdomen is also done to rule out associated anomalies. Skeletal survey is done to rule out skeletal anomalies.

Management includes psychological counselling along with creation of neovagina. Neovagina can be achieved by non-invasive, non-surgical methods by serial dilatation of vagina with vaginal dilators. However, it can be done only if vaginal dimple is present. In absence of vaginal dimple/ failure of non-surgical method or patient refusal to dilators, surgery is done to create neovagina. Various techniques of vaginoplasty are available which are based either on traction or on grafts. Surgery can now be done laparoscopically also. 
The authors hereby review the literature of MRKH syndrome regarding its embryology, etiopathogenesis, approach to work up, management and future prognosis about pregnancy.

\section{EMBRYOLOGY}

The female reproductive tract develops from a pair of Müllerian ducts. ${ }^{4}$ Following structures are derived from Müllerian duct: uterus, cervix, fallopian tube and the upper two-thirds of the vagina. The ovaries and lower third of the vagina have different embryological origins. Ovaries are derived from germ cells that migrate from the primitive yolk sac while lower one third of vagina is derived from sino-vaginal bulb. Normal development of the Müllerian ducts occurs in three phases: organogenesis, fusion and septal resorption. During first phase i.e. Organogenesis, bilateral Müllerian duct is formed. Failure of this phase results in agenesis or hypoplasia of uterus or unicornuate uterus. During second phase, fusion of Müllerian ducts leads to formation of uterus with a central septum. Failure of this step results in a bicornuate or didelphys uterus. Septal resorption is the third phase during which resorption of the central septum occurs. Failure of this stage results in a septate or arcuate uterus.

Based on the type of malformation, The American fertility association has classified Müllerian duct anomalies into 7 types as shown in Figure $1 .^{5}$ Of this, MRKH syndrome is class I Müllerian duct anomaly.

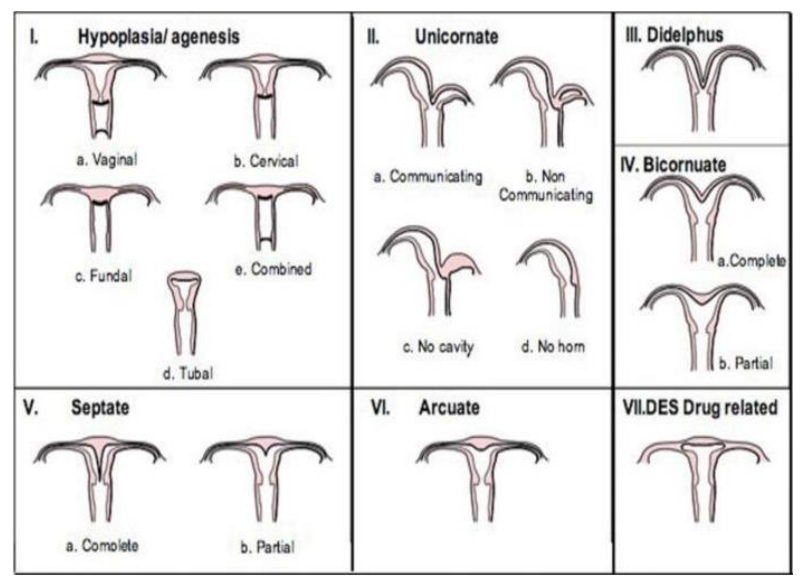

Figure 1: Classification of Mullerian duct anomalies by American fertility society. ${ }^{5}$

\section{ETIOPATHOGENESIS}

Various theories have been proposed for its pathogenesis, which are as follows:

Girdhani et al has described that MRKH syndrome occurs due to deficiency of estrogen or gestogen receptors. ${ }^{6}$ This deficiency leads to inhibition of development of Müllerian duct and hence prevents formation of structures which are derived from Müllerian duct.
Another theory was proposed by Pavanello et al who described the genetic basis of syndrome. ${ }^{7}$ They found the genetic cause of MRKH syndrome especially type B, in which renal association is found in form of renal agenesis (unilateral/ bilateral). The gene was found to be single and autosomal dominant with variable expression.

Cramer et al proposed the biological basis of MRKH syndrome. ${ }^{8}$ According to this theory, vaginal agenesis occurs due to decreased activity of Galactose-1phosphate uridyl transferase enzyme (GALT). They found that fetal/ maternal mutation of GALT enzyme leads to its decreased activity which causes vaginal agenesis.

Nodale $\mathrm{C}$ et al explained the gene expression profile of patient with MRKH syndrome. ${ }^{9}$ It was found that multiple genes are involved but two of them have strongest association which are HOXA gene and WNT-4 gene. HOXA-10 gene is associated with development of uterus, HOXA-11 gene with fallopian tube and cervix, HOXA-13 gene with vagina. Also, HOXA gene is found to be associated with development of kidney, bone and vascular structures, thus explaining the association of MRKH syndrome with other anomalies.

In another study by Bingham $\mathrm{C}$ et al and Linder $\mathrm{TH}$ et al, genital malformations such as bicornuate uterus, uterus didelphys and Müllerian aplasia were occasionally found associated with renal anomalies in some familial aggregates showing mutations within the TCF2 gene. ${ }^{11}$ The TCF2 gene (formerly v-HNF1 or HNF-1 $\beta$ ) was originally found associated with MODY-type diabetes and with diabetes mellitus, renal cysts and other renal developmental disorders. So, Defects of this gene can thus account for some rare cases of Müllerian malformations associated with familial cases with history of diabetes or renal disorders.

\section{CLASSIFICATION OF MRKH SYNDROME}

Müllerian duct anomalies have been classified into different forms. Following are the classifications.

The American fertility association has classified Müllerian duct anomalies into 7 types as shown in Figure 1. ${ }^{5}$ Of this, MRKH syndrome is class I Müllerian duct anomaly. It is further classified into:

Type A

Isolated syndrome characterised by absent uterus and upper two third of vagina with normal bilateral ovaries and no associated anomalies.

Type B

Associated with ovarian agenesis, renal anomalies, skeletal abnormalities, cardiac defects and hearing/ ocular anomalies. Renal anomalies can be renal agenesis, 
ectopic kidney, hyperplasia, malrotation or horse shoe kidney.

In study by Oppelt et al, associated malformations were found in almost 50\% of patients, of which renal and skeletal complications were most frequent. ${ }^{12}$ Renal anomalies were found in $30 \%$ of cases of which most common was renal agenesis.

Tarry and Duckett has classified Müllerian duct anomalies according to physical findings, ultrasound report and findings on laparoscopy. ${ }^{13}$ Grade 0-4 was assigned referring to extent of Müllerian duct system affected. Each side is graded separately. Letter ' $M$ ' was used to refer Müllerian duct. Following is the grading:

- M0: unilateral system normally formed but unfused/ retained septum.

- M1: vaginal agenesis alone. Uterus normal.

- M2: vaginal and uterine agenesis.

- M3: total Müllerian agenesis.

- M4: Müllerian and ovarian agenesis.

\section{APPROACH TO WORK UP}

Typically, a young girl presents to OPD with complaint of primary amenorrhea. Primary amenorrhea is defined as failure to achieve menarche till age of 14 years in absence of normal secondary sexual characters or till 16 years irrespective of secondary sexual characters. ${ }^{14}$ The most common cause of primary amenorrhea is gonadal pathology followed by MRKH syndrome. ${ }^{15}$ First of all, in such girls, age should be confirmed. $\mathrm{X}$ ray of upper extremity is done for age confirmation. Secondly, general physical examination and local vaginal examination is done to look for secondary sexual characteristics and vaginal opening respectively. In MRKH syndrome, usually all secondary sexual characteristics are normal and blind vagina is found.

After history and examination, investigations are done including endocrine test, radiological evaluation and karyotyping study. Endocrine evaluation includes hormonal profile i.e. LH, FSH, Estrogen, Testosterone, $\mathrm{TSH}$ and prolactin. Usually, in MRKH syndrome, hormonal profile is normal. On radiological evaluation, ultrasound is done on which absent uterus and cervix is found with mostly normal bilateral ovaries. For confirmation of diagnosis and surgical planning, MRI abdomen and pelvis is the investigation of choice. On MRI, most common finding is absent uterus and cervix with absence of upper $2 / 3^{\text {rd }}$ of vagina. Bilateral ovaries and lower vagina are found to be normal. MRI abdomen helps to see the associated anomalies. Skeletal survey is done to rule out skeletal anomalies. On karyotyping, normal 46 XX karyotype is found in these girls. In 1982, Smith et al reported that MRKH girls have normal $46 \mathrm{XX}$ genotype. ${ }^{16}$ Similar findings were reported by Cabra et al and Orozo Sanchez et al. ${ }^{17,18}$ The whole approach is summarised in Figure 2.

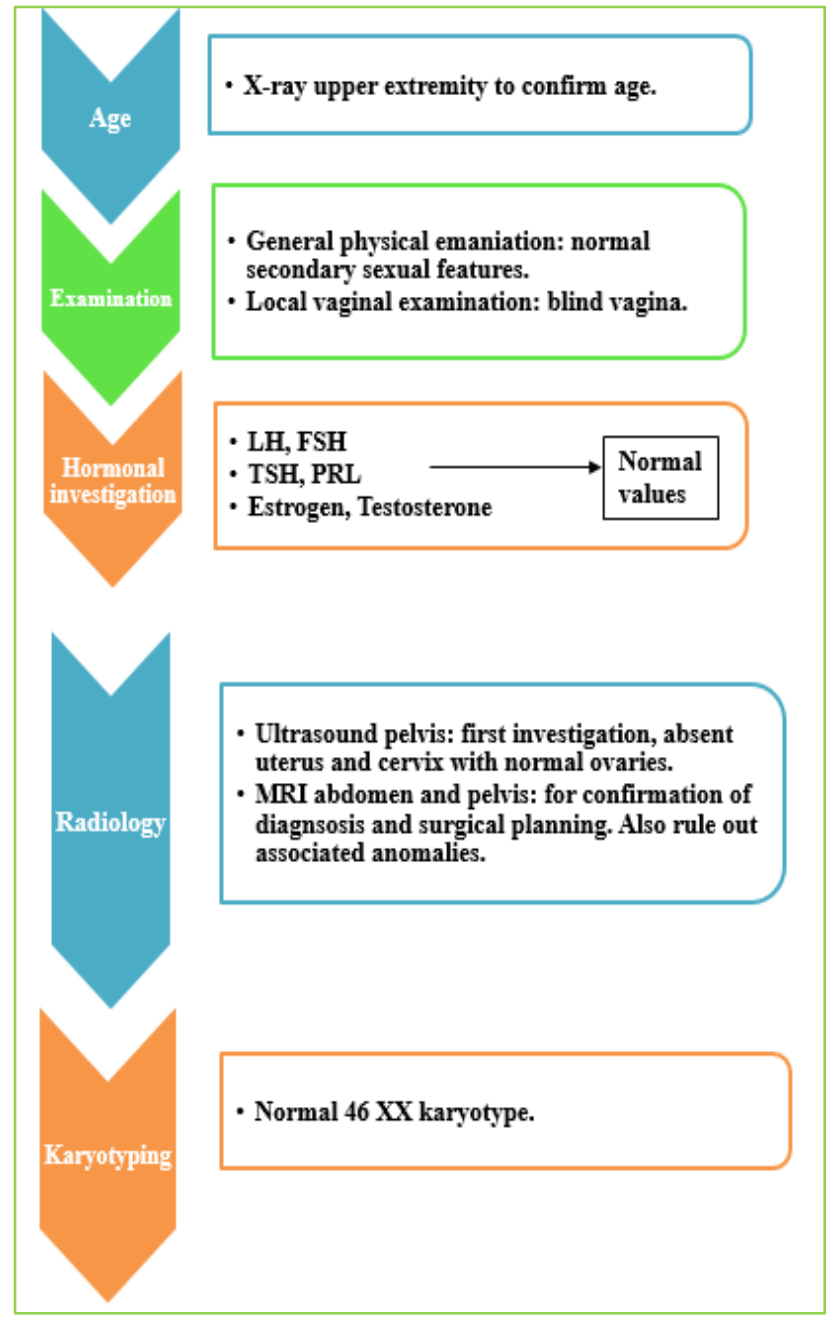

Figure 2: Flowchart showing approach to work up the patient of primary amenorrhea.

\section{DIFFERENTIAL DIAGNOSIS}

The immediate differential diagnosis of MRKH syndrome is androgen insensitivity syndrome (AIS). AIS occur due to inactivating mutation of androgen receptor thus, leading to absence of development of male characters. In AIS, young girl presents with primary amenorrhea with scarce pubic and axillary hair growth. On investigation, no uterus, cervix and ovaries are seen, rather intraabdominal testicles are found. On karyotyping, genotype $46 \mathrm{XY}$ is found. In AIS, surgery needs to be done to remove gonads due to risk of gonadal malignancy.

\section{ROLE OF LAPAROSCOPY}

Laparoscopy is usually not required for diagnosis of these cases, since it is expensive and invasive. However, in cases where patient presents with pelvic symptoms, diagnostic laparoscopy is done. Surgical treatment in form of vaginoplasty is now-a-days is combined with laparoscopy procedures. Recently, authors encountered a case of a young 17-year-old girl, who presented to our 
OPD with complaint of primary amenorrhea. Complete work was done, and she was diagnosed with MRKH syndrome type A with an ovarian cyst. Patient and family were counselled and advised surgery for cystectomy. Vaginoplasty was advised at a later age.

However, parents wanted to get combined surgery of cystectomy and vaginoplasty thus took the decision of surgery at later age only. But, after few months, she presented to emergency department with complaint of acute pain in lower abdomen. On MRI, huge thin walled complex ovarian cyst of size $97 \times 87 \times 93 \mathrm{~mm}$ was found (Figure 3).

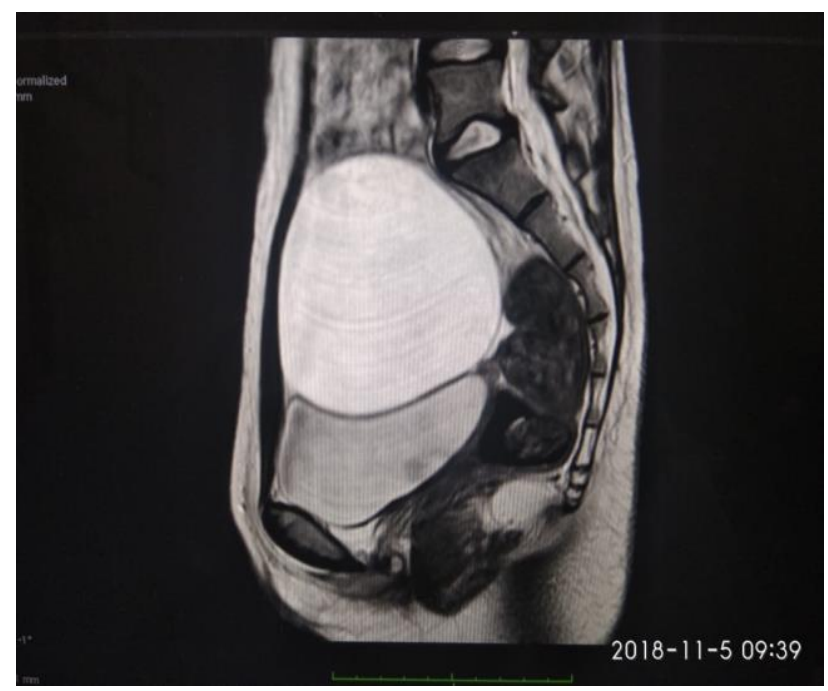

Figure 3: Image of MRI pelvis showing absence of uterus, cervix and vagina along with presence of huge ovarian cyst.

Laparoscopy was done, on which huge ovarian cyst was found with torsion (Figure 4 and 5). Ovary was detorted, and cystectomy was done.

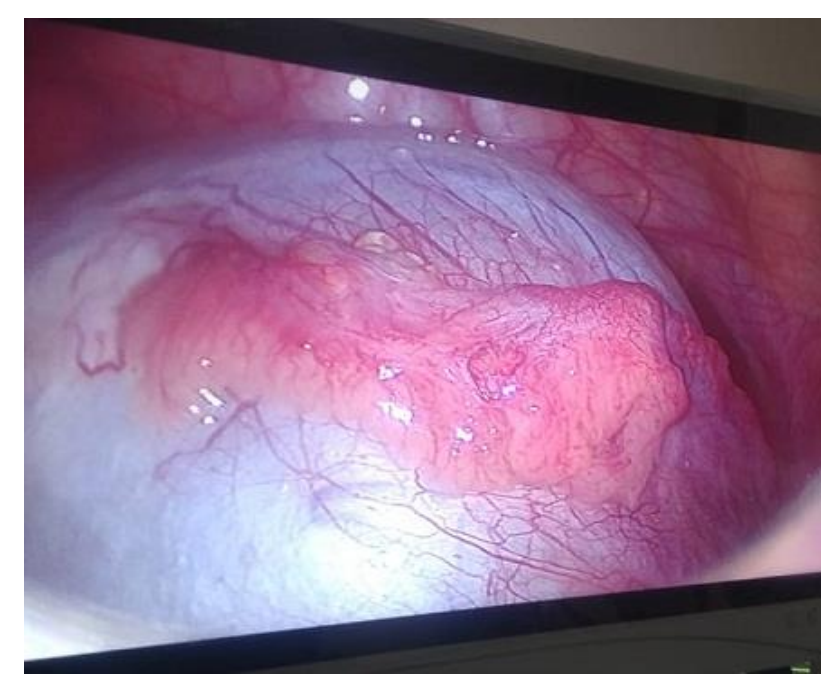

Figure 4: Image on laparoscopy showing huge ovarian cyst.

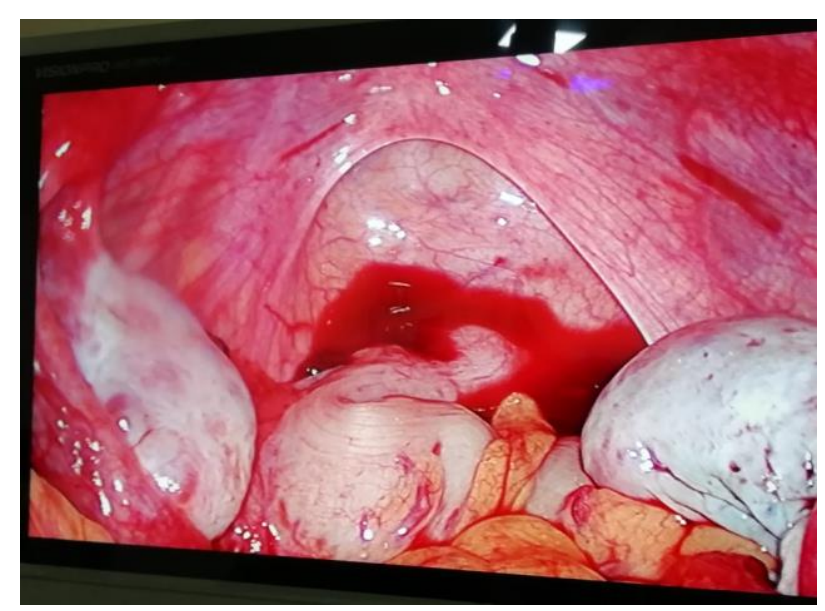

Figure 5: Absence of uterus and cervix with normal bilateral ovary after cystectomy.

\section{MANAGEMENT}

Management of MRKH syndrome includes both psychological counselling and surgical treatment. When a young girl is diagnosed with such syndrome, it is a big psychological distress to both patient and the whole family. Thus, it is recommended that patient and family should be counselled before and after treatment. Group programs are also helpful for further re-assurance.

\section{Non-surgical treatment}

Non-surgical management includes serial dilatation with vaginal dilators. Different techniques have been described, of which most commonly used technique is Frank's technique.

Frank's described a method in which vaginal dilatation is done by vaginal mould daily for 20 minutes by patient herself. ${ }^{19}$ Progressively, length and width of dilator is increased. Usually, six months is required to reach functional depth and width.

Ingram described a method in which progressive dilators are attached on a bicycle seat and patient is asked to provide perineal pressure by sitting and slightly leaning forward. ${ }^{20}$

Few disadvantages associated with these methods are urethritis, cystitis, vesico-vaginal fistula formation or secondary prolapse. But being a non-invasive method with high success rate $(78 \%$ to $92 \%)$, it is recommended as a first line therapy. ${ }^{21,22}$ However, it can be done in only those cases where vaginal dimple of at least $2-4 \mathrm{~cm}$ length is present.

\section{Surgical treatment}

Various surgical techniques have been described. These techniques are of two types: 
a. Traction based: Vechietti procedure (laparoscopic/ open)

b. Graft based: Abbe-McIndoe technique (vaginal approach, skin grafting), Intestinal vaginoplasty (combined vaginal and open/laparoscopic approach), Davydov technique (combined vaginal and laparoscopic approach, peritoneal graft).

In Vecchietti procedure, laparoscopically, an olive is attached to the vaginal dimple, the thread attached to this olive is passed to the female pelvis via vesico-rectal space, and then taken out through anterior abdominal wall, thereby connected to the traction device. ${ }^{23}$ Thus, traction is giving to olive which helps in creating new vagina. Slowly, this traction is increased day by day. Once functional length of $7-8 \mathrm{~cm}$ is achieved, the olive is removed, and girl is advised to either start intercourse or use vaginal dilators to maintain the length. Since this procedure requires very careful dissection, so it is done in only surgically naive tissue.

In graft-based techniques, a graft is used to create neo vagina. This graft can be skin graft, bowel segment or a bioengineered tissue. Various techniques obtain graft from different sites.

The Abbe-McIndoe technique is the most commonly used technique for vaginoplasty. ${ }^{24}$ In this technique, after creating a space between bladder and rectum, vaginal mould is placed. This vaginal mould is placed by putting skin graft over a vaginal stent. Split thickness tissue graft is obtained from anterior thigh or buttock. After healing of tissues, vaginal dilators are used, or intercourse is done to maintain the vagina.

In intestinal vaginoplasty, segment of sigmoid colon, ileum or jejunum is obtained via open or laparoscopic approach. The intestinal tissue provides lubrication. The disadvantage of this method is excessive vaginal discharge can occur and secondly, obtaining intestinal tissue via bowel resection and anastomosis increases the morbidities. $^{25}$

In Davydov procedure, an autologous peritoneal graft is used for vaginoplasty. ${ }^{26}$ Laparoscopically, peritoneum graft from pouch of Douglas is dissected and mobilised. After creating vaginal space, peritoneum is reached and then mobilised peritoneal sac is opened and pulled downward to connect the vaginal epithelium with graft taken from peritoneum of pouch of Douglas.

Various studies have been done to compare results of surgical and non-surgical techniques and also compare different surgical procedures. These are the results of various studies:

Morcel $\mathrm{K}$ et al did a study to compare sexual and functional results after creating neovagina via nonsurgical and surgical techniques in girls with MRKH syndrome. ${ }^{27}$ Out of 40 women who enrolled in the study,
20 were treated by Frank's method while other 20 were managed by surgical techniques (12 cases via sigmoid vaginoplasty and 8 cases via Davydov procedure). It was found that functional sexual outcomes were similar after surgical and non-surgical techniques. Thus, it was concluded that Frank's method should be proposed as first line therapy because it is less invasive than surgical procedures. Surgical reconstruction should be done in the case of failure of non-surgical technique or of refusal by the patient.

A study was done by Willemsen WN et al, to compare long term results after nonsurgical and surgical treatment (Davydov procedure) of vaginal agenesis in MRKH syndrome. ${ }^{28}$ It was found that long-term outcomes of both Frank dilation and Davydov procedure in experienced hands were good. However, when surgical management was preceded by non-surgical Frank's dilatation method, no significant difference was found. The major complications found after surgical therapy were formation of granulation tissue $(23 \%)$ and tendency to obliterate neovagina (12\%).

In a study done Ding JX et al, comparison was done between laparoscopic peritoneal vaginoplasty (Davydov prodeure) and acellular porcine small intestinal submucosa (SIS) graft. $^{29} 34$ patients were operated via SIS graft and 41 patients underwent Davydov procedure. It was found that the operating time and estimated peroperative blood loss was significantly lesser while using SIS graft. However, SIS graft is very costly (\$3525 per graft), thus significantly increasing the cost of surgery. Overall, it was concluded that vaginoplasty using SIS graft is successfully achieved in women with MRKHS, and the anatomical and functional outcomes of this procedure are comparable to laparoscopic peritoneal vaginoplasty.

Kuessel L et al published a study in which neovagina was created in a 20 -year-old woman with MRKH syndrome, by using Wharton-Sheares-George method. ${ }^{30}$ In this technique, the rudimentary Müllerian ducts were dilated incrementally by pushing Hegar dilators in the direction of the pelvic axis, and the resulting median raphe was then intersected using diathermy. Subsequently, a vaginal mold is inserted into the newly created cavity and held in position by two sutures. A mean vaginal length of $8.3 \mathrm{~cm}$ and width of $3.3 \mathrm{~cm}$ was achieved. No major Intraoperative and post-operative complications or prolapse were reported till date. Overall, it was concluded that Wharton-Sheares-George method of vaginoplasty is a minimally invasive, quick and safe surgical option that does not require allogenic or autologous transplants, nor does it require traction devices or specialized surgical equipment and provides anatomically and functionally successful outcomes.

Callens $\mathrm{N}$ et al gave an update on surgical and nonsurgical treatment for vaginoplasty. ${ }^{19} \mathrm{~A}$ research of all published literature was conducted from 1898 to March 
2013 using Pubmed, Cochrane Library and Web of Science. A total of 190 studies are analysed. It was found that when anatomical success was defined as a length of $\geq 7 \mathrm{~cm}$ and functional success as coitus, all vaginoplasty techniques yielded significantly higher success rates $(>90 \%)$ as compared to non-surgical techniques $(75 \%)$. However, overall complication rates were significantly lower within the vaginal dilation groups when compared with the different vaginoplasty techniques. Thus, vaginal dilation recommended as first choice treatment was found to be justified. Among surgical techniques, Traction vaginoplasty seems to have the highest anatomical (99\%) and functional success rates $(96 \%)$, whereas both splitand full-thickness skin graft procedures and intestinal procedures have the lowest successful outcomes (8395\%). Thus, the laparoscopic Vecchietti procedure is considered an appropriate surgical option in patients who are poorly compliant and had failed dilation therapy, or for those who do not want to start with vaginal dilation therapy.

\section{FUTURE ISSUE OF PREGNANCY}

Girls with MRKH syndrome have two issues of major concern, one is about sexual activity and other is future pregnancy. The sexual activity is achieved by creating neovagina by either non-surgical or surgical techniques as described in management segment. However, another matter of concern is to bear children. In women with normal ovarian function, pregnancy can be achieved by new fertilization techniques i.e. in-vitro fertilization followed by embryo transfer in surrogate mother. The response to treatment in terms of number of oocytes retrieved, fertilization rate, embryo quality and pregnancy rate has been reported to be slightly lower than average in comparison for infertile patients. ${ }^{31}$

\section{CONCLUSION}

MRKH syndrome is a rare congenital disorder characterized by uterine and vaginal aplasia. Typically, presentation is primary amenorrhea with normal secondary sexual characters, blind vagina, absence of uterus and cervix on ultrasonography with normal $46 \mathrm{XX}$ karyotype. Patient and family need urgent psychological counselling. Neovagina is firstly created by serial vaginal dilators. In failure of non-surgical techniques or women refusal to do so, vaginoplasty is done by either open/ laparoscopic techniques. Pregnancy can be achieved by using latest in vitro fertilization techniques and surrogacy.

Funding: No funding sources Conflict of interest: None declared Ethical approval: Not required

\section{REFERENCES}

1. Griffin JE, Edwards C, Madden JD, Harrod MJ, Wilson JD. Congenital absence of the vagina. The
Mayer-Rokitansky-Kuster-Hauser syndrome. Ann Intern Med. 1976;85:224-6.

2. Folch M, Pigem I, Konje JC. Mullerian agenesis: etiology, diagnosis, and management. Obstet Gynecol Surv. 2000;55:644-9.

3. Varner RE, Younger JB, Blackwell RE. Mullerian dysgenesis. J Reprod Med. 1985;30:443-50.

4. Chandler T, Machan LS, Cooperberg PL, Harris AC, Chang SD. Müllerian duct anomalies: from diagnosis to intervention. Brit J Radiol. 2009;82(984):1034-42.

5. The American fertility society. The American fertility society classifications of adnexal adhesions, distal tubal occlusion, tubal occlusion secondary to tubal ligation, tubal pregnancies, Müllerian anomalies and intrauterine adhesions. Fertil Steril. 1988;49(6):944-55.

6. Ghirardini G, Segre A. Vaginal agenesis (MayerRokitansky-Küster-Hauser syndrome): recent etiopathogenetical and anatomical views. Clin Exp Obstet Gynecol. 1982;9(2):98-102.

7. de Cássia M. Pavanello R, Eigier A, Otto PA, Optiz JM, Reynolds JF. Relationship between MayerRokitansky-Küster (MRK) anomaly and hereditary renal adysplasia (HRA). Am J Med Genetics. 1988;29(4):845-9.

8. Cramer DW, Goldstein DP, Fraer C, Reichardt JK. Vaginal agenesis (Mayer-Rokitansky-Kuster-Hauser syndrome) associated with the N314D mutation of galactose-1-phosphate uridyl transferase (GALT). MHR: Basic Sci Reprod Med. 1996;2(3):145-8.

9. Nodale C, Ceccarelli S, Giuliano M, Cammarota M, D'Amici S, Vescarelli E, et al. Gene expression profile of patients with Mayer-Rokitansky-KusterHauser syndrome: new insights into the potential role of developmental pathways. PloS One. 2014;9(3):e91010.

10. Bingham C, Ellard S, Cole TR, Jones KE, Allen LI, Goodship JA, et al. Solitary functioning kidney and diverse genital tract malformations associated with hepatocyte nuclear factor-1beta mutations. Kidney Int. 2002;61:1243-51.

11. Lindner TH, Njolstad PR, Horikawa Y, Bostad L, Bell GI, Sovik O. A novel syndrome of diabetes mellitus, renal dysfunction and genital malformation associated with a partial deletion of the pseudo-POU domain of hepatocyte nuclear factor-1beta. Hum Mol Genet. 1999;8:2001-8.

12. Oppelt PG, Lermann J, Strick R, Dittrich R, Strissel $\mathrm{P}$, Rettig I, et al. Malformations in a cohort of 284 women with Mayer-Rokitansky-Küster-Hauser syndrome (MRKH). Reprod Biol Endocrinol. 2012;10:57.

13. Tarry WE, Duckett JW, Stephens FD. The MayerRokintansky Syndrome: pathogenesis, classification and management. J Urol. 1986;136:648-52.

14. Kaur KK, Allahbadia G, Singh M. An approach to a patient of amenorrhea - case report and review of literature on premature ovarian failure (POF). Electronic J Biol; 12(4). 
15. Piciu D, Piciu A, Irimie A. Thyroid carcinoma and primary amenorrhea due to Mayer-RokitanskyKüster-Hauser syndrome: A case report. J Med Case Rep. 2012;6:377.

16. Smith DW. Recognizable pattern of human malformation. In: Major problems in clinical paediatrics. Genetic. Embryologic and Clinical aspects, $3^{\text {rd }}$ ed. Philadelphia: Saunders. 1982;7:482.

17. Cabra Zurita R, Munuzuri F, Benitez EA, Barroso G. Congenital absence of the vagina. MayerRokitansky-Kuster-Hauser syndrome. Presentation of a case and review of the literature. Gynecol Obstet Mex. 1998;66:354-7.

18. Orozco-Sanchez J, Neri-Vela R, Flores-Mendez MS, Sandoval Sevilla SF, Leon-Cordova K. Congenital atresia of the vagina. Bol Med Hosp Infant Mex. 1991;48:648-55.

19. Callens N, De Cuypere G, De Sutter P, Monstrey S, Weyers S, Hoebeke P, et al. An update on surgical and non-surgical treatments for vaginal hypoplasia. Hum Reprod Update. 2014;20(5):775-801.

20. Ingram JM. The bicycle seat stool in the treatment of vaginal agenesis and stenosis: a preliminary report. Am J Obstet Gynecol. 1981;140(8):867-73.

21. Rock JA, Reeves LA, Retto H, Baramki TA, Zacur HA, Jones HW. Success following vaginal creation for Mullerian agenesis. Fertil Steril. 1983;39:809-13.

22. Roberts CP, Haber MJ, Rock JA. Vaginal creation for Mullerian agenesis. Am J Obstet Gynecol. 2001;185:1349-53.

23. Borruto F. Mayer-Rokitansky-Kuster Syndrome: Vecchietti's personal series. Clin Exp Obstet Gynecol. 1992;19(4):273-4.

24. McIndoe A. The treatment of congenital absence and obliterative conditions of the vagina. Br J Plast Surg. 1950;2(4):254-67.

25. Cai B, Zhang JR, Xi XW, Yan Q, Wan XP. Laparoscopically assisted sigmoid colon vaginoplasty in women with Mayer-Rokitansky-
Kuster-Hauser syndrome: feasibility and short-term results. BJOG. 2007;114(12):1486-92.

26. Kriplani A, Karthik SD, Kriplani I, Kachhawa G. Laparoscopic peritoneal vaginoplasty for MayerRokitansky-Küster-Hauser syndrome: an experience at a tertiary care center. J Gynecol Surg. 2018;34(2):63-7.

27. Morcel K, Lavoué V, Jaffre F, Paniel BJ, Rouzier R. Sexual and functional results after creation of a neovagina in women with Mayer-Rokitansky-KüsterHauser syndrome: a comparison of nonsurgical and surgical procedures. Eur J Obstet Gynecol Reprod Biol. 2013;169(2):317-20.

28. Willemsen WN, Kluivers KB. Long-term results of vaginal construction with the use of Frank dilation and a peritoneal graft (Davydov procedure) in patients with Mayer-Rokitansky-Kuster syndrome. Fertil Steril. 2015;103(1):220-7.

29. Ding JX, Chen LM, Zhang XY, Zhang Y, Hua KQ. Sexual and functional outcomes of vaginoplasty using acellular porcine small intestinal submucosa graft or laparoscopic peritoneal vaginoplasty: a comparative study. Hum Reprod. 2015;30(3):581-9.

30. Kuessel L, Wenzl R, Marschalek ML, Slavka G, Doerfler D, Husslein H. Using the Wharton-ShearesGeorge method to create a neovagina in patients with Mayer-Rokitansky-Küster-Hauser syndrome: a stepby-step video tutorial. Fertil Steril. 2016;106(7):e201 .

31. Esfandiari N, Claessens EA, O'Brien A, Gotlieb L, Casper RF. Gestational carrier is an optimal method for pregnancy in patients with vaginal agenesis (Rokitansky syndrome). Int J Fertil Womens Med. 2004;49(2):79-82.

Cite this article as: Jain N, Kamra JH. MRKH syndrome: a review of literature. Int J Reprod Contracept Obstet Gynecol 2018;7:5219-25. 